least of its attractions is its literary style, the fruit doubtless of its author's original training in the classics, in which she took honours at our premier university. We strongly commend her book to all who love clear, sound thinking and scholarly writing.

\section{THERAPEUTIC ELECTRICITY AND ULTRAVIOLET RADIATION}

Edited by Sidney Licht, M.D. First edition. Pp. 343, with a preface and index. Published by Elizabeth Licht in 1959. \$10 (in this country £3 $17 \mathrm{~s}$.).

This is the fourth volume of a series by the editor, called Physical Medicine Library, which when complete will exhaustively cover the whole field of physical medicine. The main appeal, therefore, will be as a reference work for the physical medicine specialist rather than a textbook for the student, who in any event could ill afford the price. It follows the same pattern as the previous volumes in that the ground covered is divided between several contributors-nine in this case-some of whom take a long time to say what they have to say and do so with some overlapping of information. The historical section and bibliographies are unusually long. The authors of the section of physiological effects of ultra-violet radiation fail in their intention to relate clearly the observed effects in man and mammals to those seen in the biological laboratory on protozoa and plants. The chapters on clinical electric stimulation and iontophoresis and instrumentation for and clinical uses of ultra-violet radiation are the best in their respective sections. The table on page 201 needs a mathematical alteration at the top of column three, headed 'Millimicron.' On page I I I it is not made clear that fibrillation potentials are detected at electromyographic examination three or four days after denervation is complete. The inclusion of a chapter on electro-sleep therapy is somewhat sensational and of little interest to any but the psychiatrist. The claims made for the work on the inside of the paper cover are extravagant and intended largely, no doubt, as sales talk.

\section{BREAST CANCER}

The Second Biennial Louisiana Cancer Conference, New Orleans, January 22-23, $195^{8}$

Edited by Albert Segaloff, M.D. Pp. 257, illustrated. St. Louis: The C. V. Mosby Co. Distributed in Great Britain by Henry Kimpton, London. 1958. £i 17s. 6d.

'This volume records the formal papers and the panel discussions of the conference. The papers are grouped under the headings of basic biology, definitive treatment and hormonal therapy. Worthy of special note are the papers of Dr. Ian Macdonald on clinical evidence of biological variability in mammary carcinoma, of Dr. 'Thal and of Dr. Urban on the extended radical operation, and of Dr. Haagensen on criteria of operability. The panel $\mathbb{\mathbb { D }}$ discussions are reported freely and informally with $c$ such phrases as "even if I miss my plane and have to walk to Tucson I have to take a crack at that,' and as a result are valuable in elucidating the $\overline{0}$ opinions of the participants. The volume as a whole, and in particular the papers of Dr. Macdonald and of Dr. Haagensen, reflect the present mood of questioning in the management of breast cancer: 0 How important is early operation? Are certain cases, though operable, best treated by other means than operation? If so, which cases, and how should they be treated?

\section{INSULIN TREATMEN T IN PSYCHIATRY}

Edited by M. Rinkel and H. E. Himwich. Pp. Фे XXIX +386 . New York: Philosophical Library. $\stackrel{\oplus}{\oplus}$ I959. 39s.

This book deserves close study by all psychiatrists. It includes the papers read and ensuing or discussions at the International Conference held at the New York Academy of Medicine in 1958, $\frac{}{7}$ during which all aspects of insulin treatment in psychiatry were covered.

With the advent of electroplexy, neuro-surgical procedures and certain tranquillizers since Sakel's introduction of insulin coma treatment over 30 years ago it was time to take stock of their relatike benefits in view of the decline in use of the latte⿳亠二口犬 This volume certainly affords refreshing and in? structive reading. It is divided into three parts: historical contributions, physiochemical research and clinical research. An appendix contains a translation of Sakel's address at the University of Vienna the previous year at the 30-year celebration of his discovery.

Although much of the content concerns insulin coma treatment, due attention is paid to modified insulin therapy and the possible or actual relative advantages of dual treatments, such as I.C.T. and E.C.T. or I.C.T. and tranquillizers. Whilst it may be argued that chlorpromazine or phenothiazine $\dot{0}$ derivatives are of definite therapeutic value, it is 3 . emphasized that insulin comas still have, or should $\delta$ have, a place in the treatment of certain schizophrenics, but that particular attention should be paid to Sakel's original instructions on technique. $\frac{7}{J}$ 'This book and the conference which led to its pub- $\rightarrow$ lication could give rise to second thoughts in the few psychiatric hospitals in this country where insulin treatment units no longer function.

\section{A MANUAL OF PSYCHIATRY}

By K. R. Stallworthy. Fourth edition. Pp. 365. New Zealand: N. M. Peryer Ltd. 1959. 30s. net.

'This is a carefully planned and practical book? containing an outline of normal and abnormal psychology followed by basic psychiatric medicine 